\title{
CHARACTERIZING THE CRACK DEVELOPMENT IN STRAIN-HARDENING CEMENT-BASED COMPOSITES (SHCC) BY MEANS OF ACOUSTIC EMISSION
}

\author{
IURIE CUROSU ${ }^{*}$, STEPHAN PIRSKAWETZ ${ }^{\dagger}$, VIKTOR MECHTCHERINE* \\ Technische Universität Dresden, \\ Dresden, Germany \\ e-mail: iurie.curosu@tu-dresden.de \\ mechtcherine@tu-dresden.de \\ ${ }^{\dagger}$ Federal Institute for Materials Research and Testing (BAM) \\ Berlin, Germany \\ e-mail: stephan.pirskawetz@bam.de
}

Key words: SHCC, Fiber, Tension, Fracture, Acoustic Emission

\begin{abstract}
The article at hand presents an investigation on crack development in three different types of strain-hardening cement-based composites (SHCC) subjected to uni-axial tensile loading. The aim of the work was to evaluate the applicability of acoustic emission (AE) measurements for determining the progressive damage within the material, as well as for differentiating the individual damage events by their origin and decisive mechanisms, such as matrix cracking, fiber pullout or fiber rupture. The acoustic emission method proved to be fully appropriate for recording and evaluating the fracture related processes in various types of SHCC. Valuable information on failure mechanisms and quantitative description of damage depending on SHCC composition was obtained and evaluated with respect to the measured stress-displacement curves and under consideration of fracture surfaces and crack patterns observed on the specimens.
\end{abstract}

\section{INTRODUCTION}

Strain-hardening cement-based composites (SHCC) represent a relatively new class of fiber reinforced cementitious materials that exhibit multiple cracking when subjected to increasing tensile loading after the formation of the first crack. Multiple cracking leads to a very high strain capacity and limited crack widths, which makes SHCC especially suitable for structures exposed to aggressive environmental or severe mechanical loading, both as main material and material for strengthening or repair [1]. It has been used in Japan as main material for coupling beams in a high-rise building [2,3], in bridge deck link slabs in the USA [4,5], or for retrofitting a water reservoir in Germany [6] etc. Despite the recent realization of such constructions and retrofits, with their ages hardly exceeding one decade, their inspection and monitoring is essential for validating or amending the experimentally based knowledge about SHCC's performance under various loading conditions.

In comparison to ordinary RC structures, the visual inspections of structures made of or strengthened with SHCC can lead to an underestimation of the extent of effective damage. Such damage processes as crack development in the substrate or corrosion of the steel reinforcement can be masked by the SHCC cover which shows just distributed, fine cracks [7-9]. In this case, for a reliable 
assessment of the deterioration and its causes, an in-depth examination is necessary. Although some destructive methods, e.g. core drilling, may offer a full picture of the damage, they are not always suitable. Especially in case of old, restored buildings or when a long term monitoring is intended, non-destructive techniques are highly desirable.

The acoustic emission (AE) technique has been extensively applied in monitoring concrete structures under service conditions or as accompanying measurements for mechanical tests in order to gain additional information about the active deterioration processes [10]. With regard to ordinary concrete, acoustic emissions are defined as released elastic waves resulting from crack formation events, which propagate through concrete and are detected on the surface by an $\mathrm{AE}$ sensor [10]. Besides detecting and volumetrically localizing the fracture processes [11], it allows their classification according to the fracture modes, to which waveforms with particular features are attributed $[12,13]$. In this way, the AE method is also effective in monitoring fiber reinforced concretes, in which, additionally to concrete cracking, other failure mechanisms, e.g. fiber pullout, have to be distinguished / identified [14-16]. The technique is also appropriate for monitoring strengthened structural elements where the damage at the interface between two materials should be quantified and localized [17].

There is however a clear deficiency of research on AE related to SHCC or cementitious composites with disperse microfibers. The mechanical behavior of such materials is highly dependent on failure mechanisms on micro-level and their differentiation from other macro-fracture processes might be difficult. The only $\mathrm{AE}$ study on SHCC known by the authors is a recent publication by Paul et al. [18] in which $\mathrm{AE}$ recordings accompanying tensile and bending tests on SHCC prisms and beams were presented. It was possible to differentiate matrix cracking from fiber pullout based on the weighted peak frequencies of the generated waveforms. The authors underlined the necessity for further research and analysis of additional parameters for a more detailed description of the damage processes in SHCC. Additionally, further experimental work is needed for various loading conditions and for various SHCC compositions. This would be an important step towards the implementation of the method in monitoring the behavior of structural elements made of or retrofitted with SHCC.

In the current work, three different types of SHCC were tested under uni-axial tensile loading. The differences in the SHCC compositions resulted in distinct dominating failure modes, thus, serving for a better interpretation of the $\mathrm{AE}$ recordings and their correct attribution to the corresponding fracture processes.

\section{EXPERIMENTAL DETAILS}

The quasi-static tensile testing was performed on an Instron universal testing machine with a load capacity of $100 \mathrm{kN}$. Two dumbbell specimens for each SHCC were tested under a displacement rate of $0.05 \mathrm{~mm} / \mathrm{s}$ at an age of 14 days. The effective crosssection of the specimens was $24 \times 40 \mathrm{~mm}^{2}$. To ensure non-rotatable boundary conditions, the specimens were glued in steel rings at both ends.

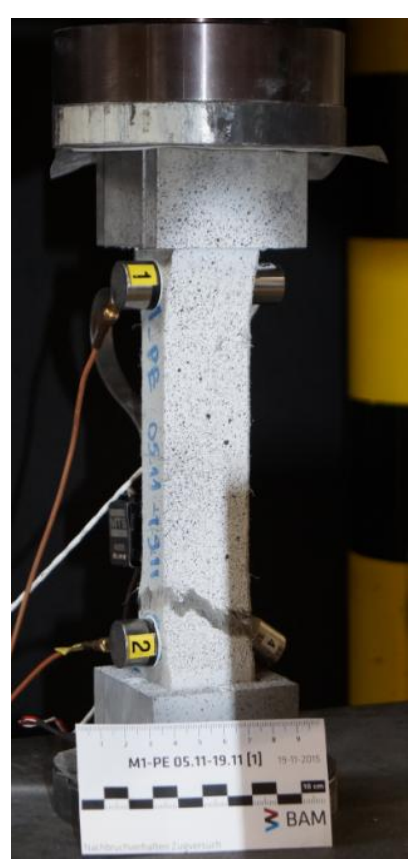

Figure 1: SHCC sample equipped with AE sensors. 
Two AE sensors type VS 150 MS were coupled by an adhesive putty (Bostik Prestik ${ }^{\circledR}$ ) at the wide ends of the specimens at a distance of $180 \mathrm{~mm}$ between them. The sensors have a nominal bandwidth of $100-450 \mathrm{kHz}$ with a peak frequency of $150 \mathrm{kHz}$. An AMSY-6 system was used to process and store the acoustic emission signals. Due to the noise emitted by the hydraulic testing machine, the detection threshold was set to $50 \mathrm{~dB}$ and frequency filter was set to $50-850 \mathrm{kHz}$.

\section{SHCC COMPOSITIONS AND TENSILE BEHAVIOR}

The differences between the SHCC mixtures under investigation consisted in the composition of cementitious matrix and fiber type, see Table 1 . The SHCCs were named according to the combinations of fiber and matrix of which they were made. M1 and M2 indicate the normal-strength and high-strength matrices respectively, while PVA and PE denote shortly the polyvinyl-alcohol and highdensity polyethylene (HDPE) fibers. Detailed fiber characteristics are given in Table 2.

Table 1: Mix compositions of the tested SHCCs.

\begin{tabular}{|l|c|c|c|}
\cline { 2 - 4 } \multicolumn{1}{c|}{} & $\begin{array}{c}\text { M1_PVA } \\
{\left[\mathrm{kg} / \mathrm{m}^{3}\right]}\end{array}$ & $\begin{array}{c}\text { M1_PE } \\
{\left[\mathrm{kg} / \mathrm{m}^{3}\right]}\end{array}$ & $\begin{array}{c}\text { M2_PE } \\
{\left[\mathrm{kg} / \mathrm{m}^{3}\right]}\end{array}$ \\
\hline $\begin{array}{l}\text { CEM I 42.5 } \\
\text { R-HS }\end{array}$ & 505 & 505 & - \\
\hline $\begin{array}{l}\text { CEM I 52.5 } \\
\text { R-SR3/NA }\end{array}$ & - & - & 1460 \\
\hline fly ash & 621 & 621 & - \\
\hline silica fume & - & - & 292 \\
\hline quartz sand & 536 & 536 & 145 \\
\hline superplastis. & 10 & 25 & 25 \\
\hline $\begin{array}{l}\text { PVA fibers } \\
\text { (2 \% by vol.) }\end{array}$ & 26 & - & - \\
\hline $\begin{array}{l}\text { HDPE fibers } \\
\text { (2 \% by vol.) }\end{array}$ & - & 20 & 20 \\
\hline water & 338 & 338 & 315 \\
\hline VMA & 4.8 & 4.8 & - \\
\hline
\end{tabular}

M1_PVA is a 'typical', normal-strength SHCC, which has been investigated by the authors in other studies as well, see, e.g. [19]. The fine-grained matrix has a high content of fly ash and a water-to-binder ratio of 0.3 . The matrix was specifically designed for an optimal interaction with the PVA fibers in terms of the mechanical properties of the hardened SHCC and the rheology of the fresh mix.

Table 2: Properties of the high-performance polymer fibers.

\begin{tabular}{|l|c|c|}
\hline fiber type & PVA & HDPE \\
\hline product name & Kuralon & Dyneema \\
\hline manufacturer & Kuraray & DSM \\
\hline diameter $[\mu \mathrm{m}]$ & 40 & 20 \\
\hline length $[\mathrm{mm}]$ & 12 & 12 \\
\hline tensile strength $[\mathrm{MPa}]$ & 1700 & 2500 \\
\hline Young's modulus $[\mathrm{GPa}]$ & 40 & 80 \\
\hline density $\left[\mathrm{g} / \mathrm{cm}^{3}\right]$ & 1.3 & 0.97 \\
\hline
\end{tabular}

The PVA fibers have a hydrophilic character and form a relatively strong, chemical bond with the cementitious matrix. The particular PVA fibers have however a partial oily sizing, which diminishes the strength of the bond to the matrix. Even then, since the strength of the fiber-matrix bond is proportional to the matrix strength, the combination of PVA fibers with a highstrength matrix would result in a fiber rupture soon after crack formation, thus, in brittle fracture with no subsequent multiple cracking. For this reason, when developing the highstrength SHCC M2_PE, another fiber type was chosen. Besides featuring a higher tensile strength, the high-density polyethylene (HDPE) fibers have a hydrophobic nature, which prohibits the formation of chemical bond to the cement-based matrix, thus, allowing only a mechanical interaction with the matrix. In this way, it is reasonable to combine them with a high-strength matrix and insure at least a partial delamination from the matrix and related formation of free length needed for fiber deformation and controlled crack opening. Such crack-bridging is an important condition for the pseudo-ductility of SHCC. The high-strength matrix was designed by adapting M1 for reaching a high strength on one hand, and an appropriate interaction with the HDPE fibers on the other hand. It had a high cement content and a water-to-binder ratio of 0.18 only, while binder consisted of cement and silica fume. In contrast to M1, fly 
ash was not used and the content of fine sand was significantly reduced.

As already mentioned, the reason for testing different types of SHCC was their particular mechanical behavior and fracture modes under tensile loading, which would allow for a better differentiation of the acoustic emission signals. Figure 2 presents three representative tensile stress-strain curves for the SHCCs under investigation. Their tensile behavior can be divided into three stages: the first being the elastic, crack-free stage, followed by the second - strain-hardening with multiple crack formation - and ending by the third, fracture localization and softening.

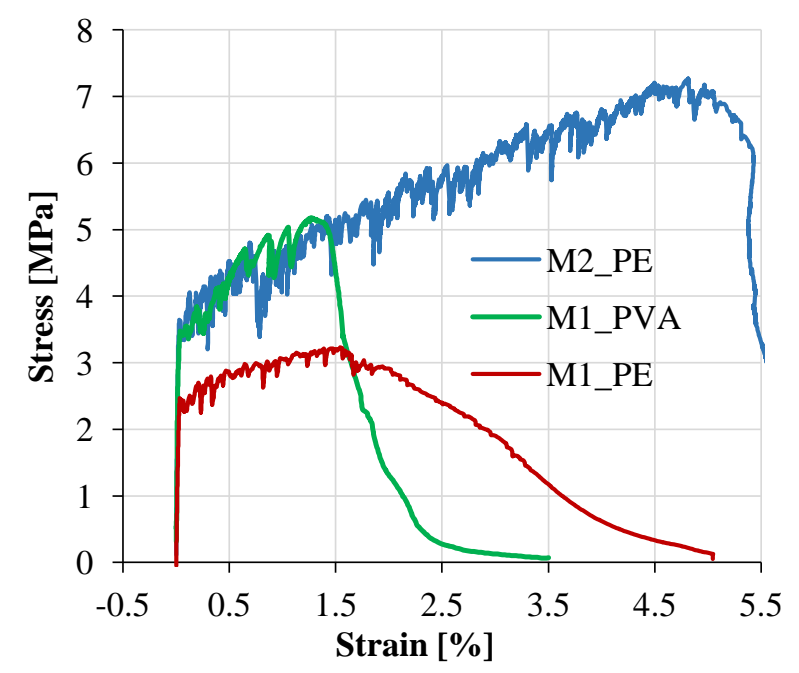

Figure 2: Representative stress-strain curves for SHCCs under investigation.

By analyzing comparatively the elastic regions of the curves presented in Figure 2, it may be noticed that the first-crack stress of M1_PVA is much higher compared to M1_PE despite the fact that this SHCC was made of the same matrix. This is because the chemical bond between the PVA fibers and the cementitious matrices leads to a good composite behavior at micro-level, arresting micro-cracks and leading to a higher firstcrack stress compared to SHCC containing hydrophilic fibers: there is no or just very little composite action before crack formation. In this case, the fibers are activated in the crackbridging phase only. More than that, such weak fiber-matrix interfaces act as microdefects, leading to an even lower first-crack stress. This can be also observed when comparing M2_PE and M1_PVA: Despite M2_PE being made with a high-strength matrix, the first crack in this SHCC forms at the same stress level as in M1_PVA made with a normal strength matrix.

The extent of strain-hardening and multiple cracking in the second phase depends on a series of factors. Here, the optimal balance between crack bridging capacity by fibers and tensile strength and fracture toughness of the matrix is essential. This micromechanical balance was achieved at its best with M2_PE, that yielded a superior multiple cracking compared to the other two SHCCs. It also has a high margin between first-crack stress and crack-bridging strength (tensile strength of the composite). These features benefit from the brittleness of the matrix M2, which exhibit a reduced resistance against crack propagation. In the case of M1_PVA the tendency to multiple cracking is limited by the higher toughness of the matrix, e.g. due to higher content of sand particles, and the lower margin between first-crack stress and tensile strength of SHCC.

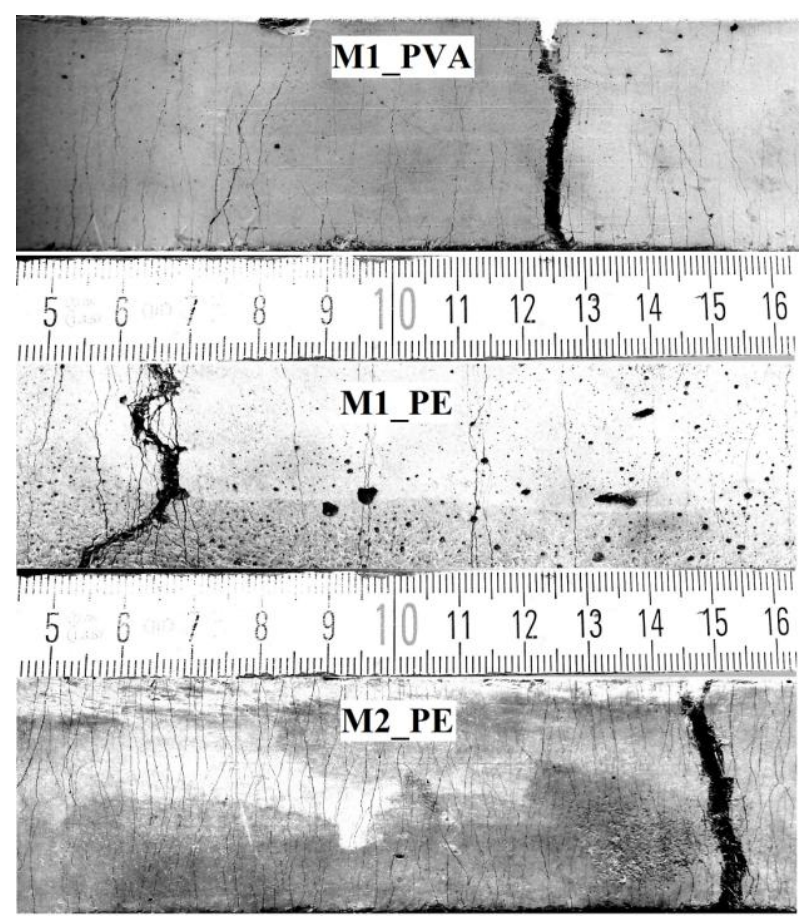

Figure 3: Multiple cracking developed by different types of SHCC in the tension tests. 
M1_PE is a "formal" combination interesting here because of its well-defined failure mode. The micromechanical conditions for strain-hardening in M1_PE are just partially satisfied. The very low crack-bridging capacity leads to a generally inferior behavior under quasi-static tensile loading and to wider cracks in comparison to the other two SHCCs, see Figures 2 and 3. The effect of weak fibermatrix bond can be also observed in the localization crack, at which M1_PE yielded a complete fiber pullout, see Figure 4, and by the shallow descending branch in the softening phase, see Figure 2. The other two SHCCs yielded a mixed fracture mode (pullout and fiber fracture), whereas the fiber pullout length in M1_PVA was limited to approximately 1-2 $\mathrm{mm}$, as can be observed in Figure 4. This is because of the slip-hardening nature of the bond between PVA fibers and cement-based matrix.

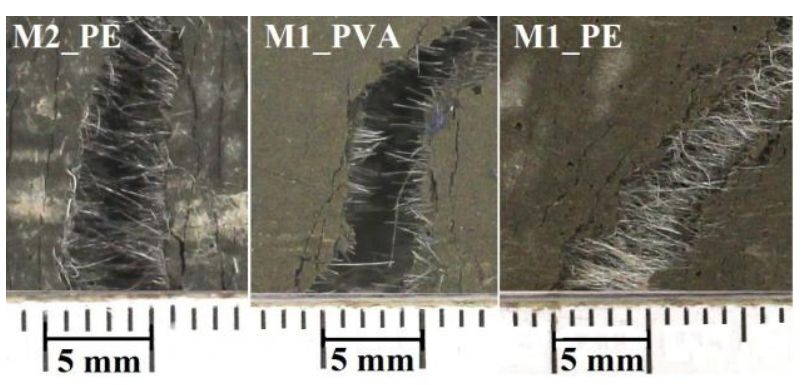

Figure 4: Fracture modes of different types of SHCC.

More detailed information on the mechanical behavior of the SHCC compositions presented in this article and the features of fiber-matrix interactions can be found in $[19,20]$.

\section{AE MEASUREMENTS}

Figure 5 presents an example of $\mathrm{AE}$ recordings accompanying a tensile test on SHCC. For the sake of presentation, the diagram corresponds to an SHCC sample made of high-strength matrix M2 and only 0.5 $\%$ volume content of HDPE fibers. The reduced fiber content, i.e. lower crack bridging capacity, in combination with the strong but brittle matrix, leads to a higher energy release during cracking (pronounced drops in stress), making the $\mathrm{AE}$ easily distinguishable with regard to crack formation. The strains as presented in Figure 2 were measured with a gauge length of $100 \mathrm{~mm}$ in the narrowed section of the specimen, while the total free length was $220 \mathrm{~mm}$. Since multiple cracking occurs along the entire specimen (also outside the strain gauge), the $\mathrm{AE}$ activity is not properly reflected in such stress-strain curve. For this reason, the AE recordings are presented here with respect to the total displacement. The black, solid curve describes the tensile behavior of the tested sample, while the red dots indicate $\mathrm{AE}$ signals detected by the two AE sensors on the upper and lower parts of the specimen.

The recorded acoustic emissions are spanning the entire displacement axis, i.e. before macro-crack formation and after localization. The strain-hardening phase is covered by clouds of points well aligned with the stress drops, showing when critical stress levels are reached and cracks form. Immediately after the stress drops, there is almost no AE activity, indicating the relaxation phases with no damage evolution. The high number of recorded hits in the softening phase indicates localization and damage concentration.

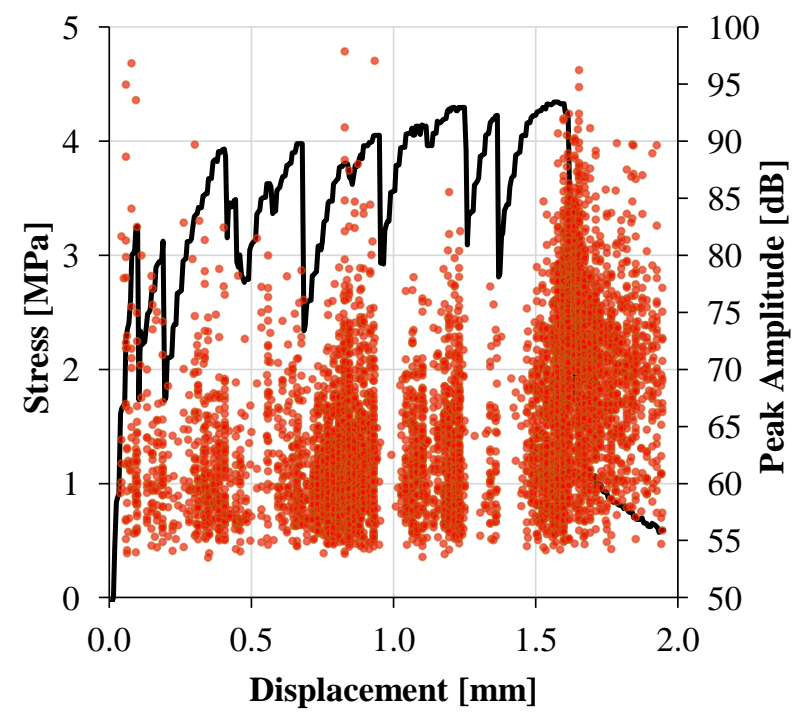

Figure 5: AE recordings during an uni-axial tension test on a M2 sample containing $0.5 \%$ of HDPE fibers.

For being able to describe the failure mechanisms behind these signals, a frequency analysis must be performed. It is known that 
waveforms with high frequencies correspond to fracture mode I (tension), while the waves with lower frequencies correspond to shear or frictional fracture modes $[12,13]$. For SHCC under uni-axial tensile loading, the tensile fracture modes can be only assigned to matrix cracking and fiber breakage, while the shear fracture modes result from the pullout of the fibers. The excited elastic waves, as they reach the AE sensors, have a broad frequency distribution. For this reason, the AE signals were characterized in the frequency domain by the weighted peak frequency (WPF) of the recorded waveforms. It is computed from the frequency center of gravity $\mathrm{f}_{\mathrm{COG}}$ and peak frequency $\mathrm{f}_{\mathrm{PEAK}}$ as follows:

$$
\mathrm{WPF}=\sqrt{\mathrm{f}_{\mathrm{COG}} \cdot \mathrm{f}_{\mathrm{PEAK}}}
$$

Even if the recorded signals are strongly influenced by the frequency response of the sensors, which show a peak frequency around $150 \mathrm{kHz}$, it is possible to distinguish between signals of higher or lower frequency contents.

In Figures 6-8 the recorded acoustic emissions for each type of SHCC are represented with respect to their weighted peak frequencies. For being able to distinguish the $\mathrm{AE}$ recorded during the strain-hardening phase from those recorded during crack localization, in Figures 6-8, the blue curves represent $\mathrm{AE}$ corresponding to the complete stress-strain curves, while the yellow curves represent just the strain-hardening (multiple cracking) phase. By comparing the areas under the yellow curves to the areas under the blue curves, the domination of hits recorded in the localization phase becomes evident. The WPFs are presented in a continuous distribution and they clearly form two peaks for all SHCCs. The approximate weighted peak frequency that separates the two peaks is $110 \mathrm{kHz}$. By attributing the lower frequencies to fiber pullout and the higher frequencies to matrix and fiber fracture, the quotients of different damage mechanisms depending on SHCC type can be deduced. Note that the "Hits" axes are scaled differently for each material. The contribution of hits from the elastic phase is very small and is not discussed here.

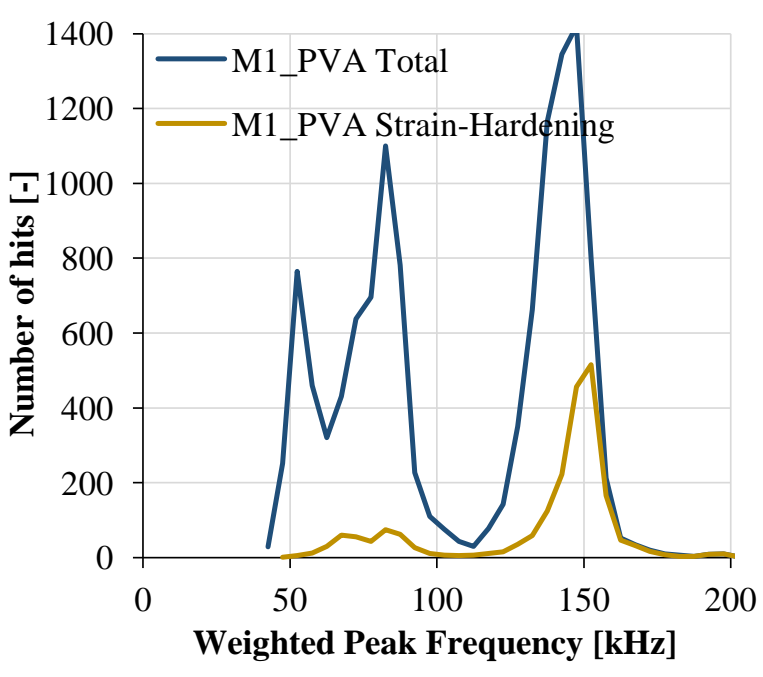

Figure 6: Frequency content of the AE for M1_PVA.

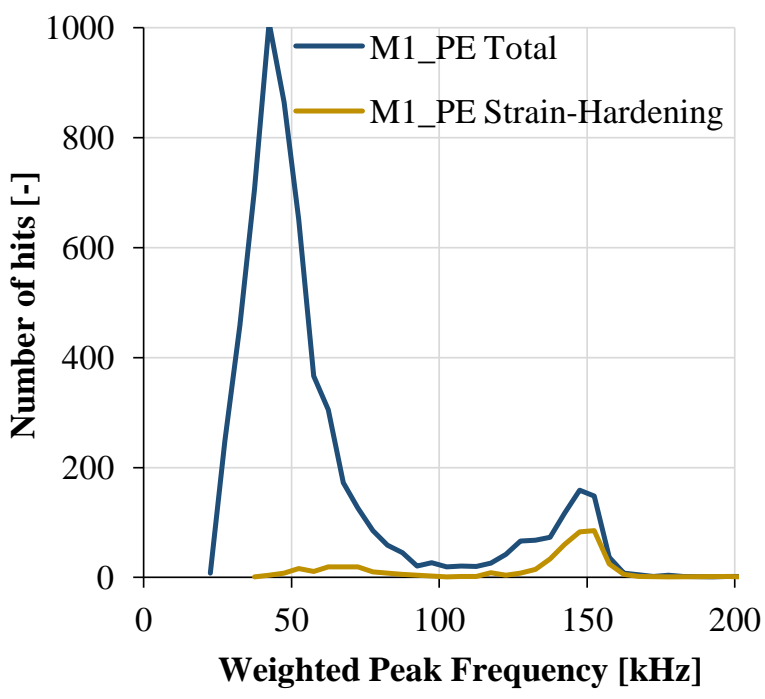

Figure 7: Frequency content of the AE for M1_PE.

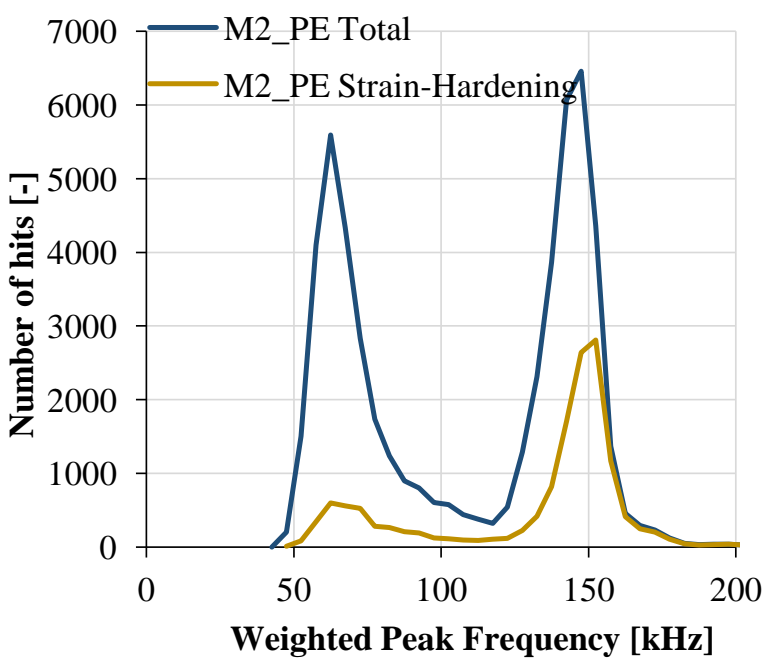

Figure 8: Frequency content of the AE for M2_PE. 


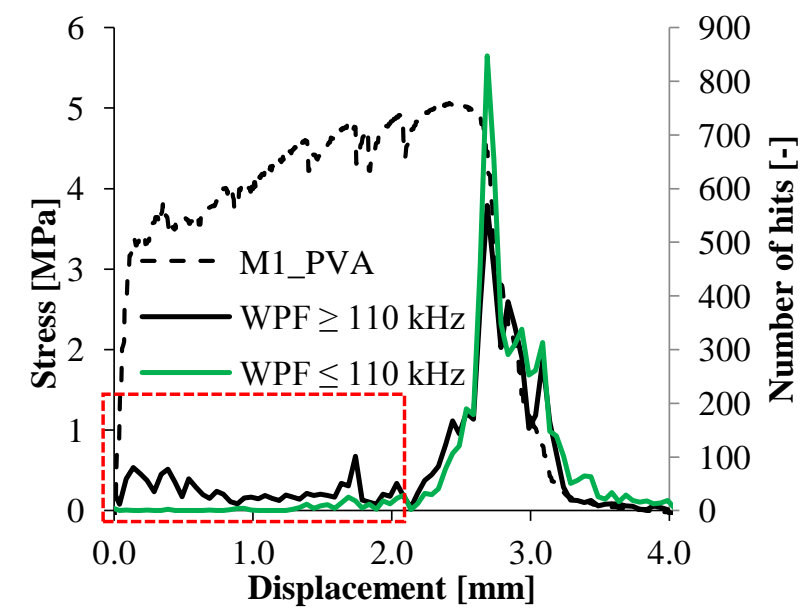

Figure 9: AE activity in two representative WPF ranges measured on M1_PVA.

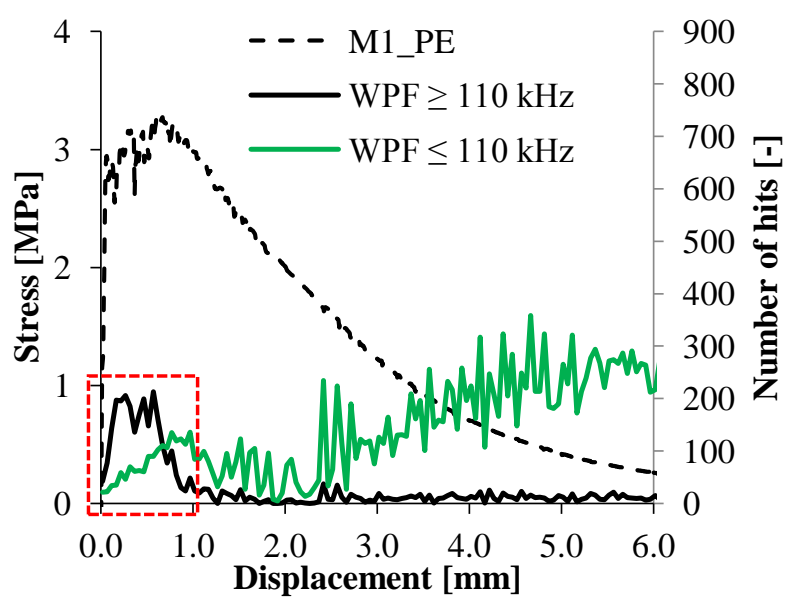

Figure 10: AE activity in two representative WPF ranges measured on M1_PE.

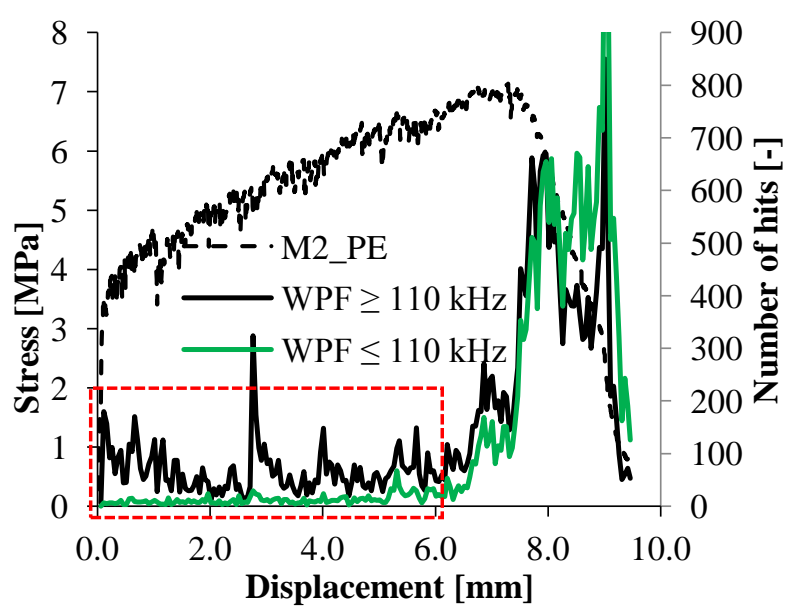

Figure 11: AE activity in two representative WPF ranges measured on M2_PE.

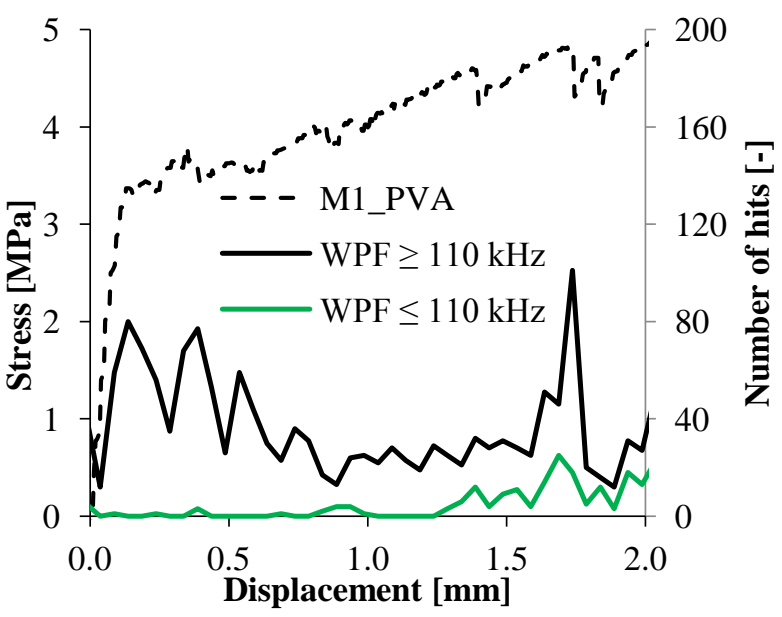

Figure 12: AE activity in two representative WPF ranges measured on M1_PVA in the strain-hardening phase.

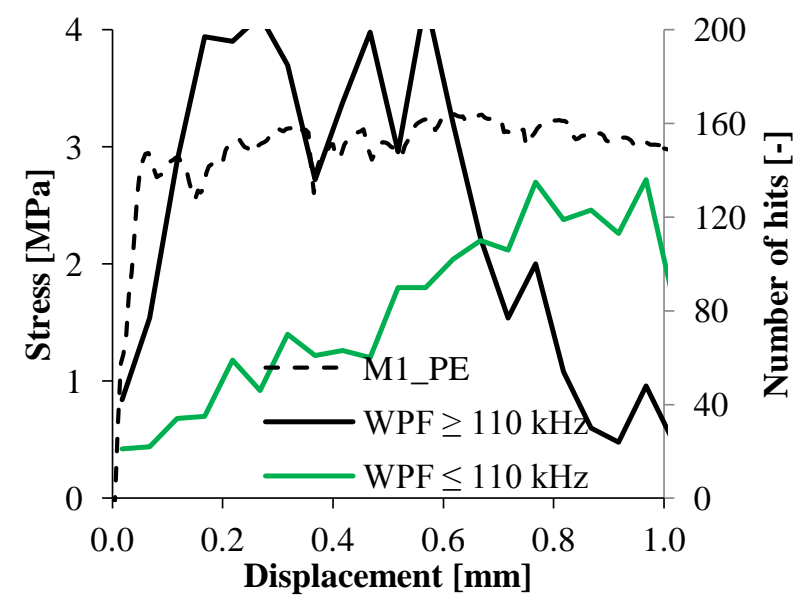

Figure 13: AE activity in two representative WPF ranges measured on M1_PE in the strain-hardening phase.

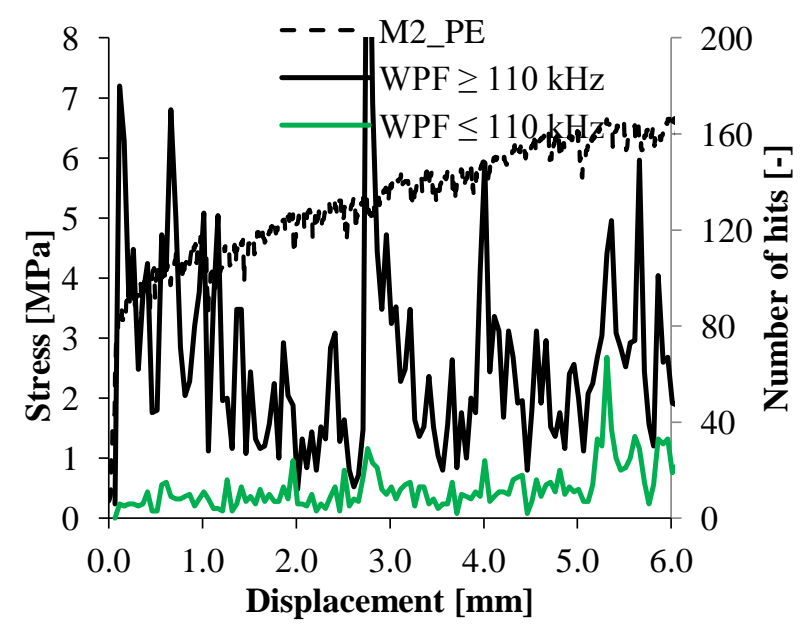

Figure 14: AE activity in two representative WPF ranges measured on M2_PE in the strain-hardening phase. 
The total number of recorded AE events in M1_PE was clearly dominated by lower frequencies as a result of the long softening phase with complete fiber pullout. The strainhardening phase was short and generated mostly hits with higher frequencies, see Figure 7. In contrast to M1_PE, in the case of M1_PVA and M2_PE, $50 \mathrm{kHz}$ was the lower margin of WPF for the signals that result from shear fracture.

Interestingly, M1_PVA showed a broader range of lower frequencies with separation in two peaks, see Figure 6. This may be related to the complex interaction between PVA fibers and cementitious matrix. Furthermore, the number of recorded hits in the lower WPF range for M1_PVA specimens is comparable to that recorded for M1_PE specimens, despite the fact that the pullout extent of M1_PVA is limited to 1-2 $\mathrm{mm}$. This indicates pronounced damage processes at the fiber-matrix interfaces occurring during fiber pullout due to the stronger bond of PVA fibers and associated slip-hardening. The fact that stronger interfaces generate more $\mathrm{AE}$ during fiber pullout can be also deduced from the high number of low WPF hits recorded for M2_PE, which yielded a lower extent of fiber pullout in comparison to M1_PE.

Figures 9-11 show the acoustic emissions grouped according to WPF and related to the stress-displacement diagrams. Also in these figures the significant contribution of the softening phase to the total AE activity is evident. As opposed to M1_PE, the AE in the softening phases of M1_PVA and M2_PE are characterized by a considerable content of higher frequencies (above $110 \mathrm{kHz}$ ). This part of $\mathrm{AE}$ contains the matrix cracking as well as fiber breakage signals. Although it is impossible to differentiate them at this observation level, the high WPF peaks represented in Figures 6 and 8 show that the strain-hardening (yellow) peaks are shifted to the right in comparison to the peaks of total AE (blue). Since massive fiber breakage is unlikely in the strain-hardening (multiple cracking) phase, but very probable in the softening phase, the development of the higher WPF peak of total AE towards lower frequencies is likely to be caused by fiber rupture. For clarifying such aspects in their future work, the authors intend to monitor $\mathrm{AE}$ activity during pullout tests on single fibers and tension tests on unreinforced matrix samples.

Figures 12-14 give a more detailed view of the $\mathrm{AE}$ records in the strain-hardening phase of each SHCC as enclosed in red boxes in Figures 9-11. As opposed to the green curves (low WPF), the black curves (high WPF) corresponding to matrix cracking do not show an increase with increasing displacement. The increasing number of $\mathrm{AE}$ corresponding to shear fracture mode (green curves) is a result of a continuous multiple cracking and, consequently, the involvement of an increasing number of fibers in the crack bridging process. This is especially noticeable for M1_PE due to the weak fiber-matrix interface and wider cracks compared to the other SHCCs. M1_PVA shows the lowest AE activity for both lower and higher WPFs, which is in agreement with the description in Section 3 with regard to the composite action of the PVA fibers with the cementitious matrix before and after crack formation.

\section{CONCLUSIONS AND OUTLOOK}

Three different types of SHCC were analyzed under quasi-static tensile loading. The mechanical testing was accompanied by AE measurements for evaluating the applicability of the $\mathrm{AE}$ technique to monitoring the damage evolution in SHCC. The acoustic emission measurements could properly detect the damage processes and classify them according to the fracture mechanisms, such as matrix cracking or fiber pullout. However, for a more accurate evaluation of the AE measurements, reference values for various $\mathrm{AE}$ parameters based on the fracture mechanisms should be obtained from tension tests on plain matrix and single fiber pullout tests. It is also desirable to adopt $\mathrm{AE}$ sensors with a broader frequency response for a more accurate differentiation of the microfracture processes, since their frequency content depends on the SHCC composition. 


\section{REFERENCES}

[1] Li, V.C. 2003. On engineered cementitious composites (ECC): A review of the material and its applications. Journal of Advanced Concrete Technology 1 (3):215-230.

[2] Kanda, T., Takaine, Y., Tomoe, S., Takahashi, M., Yamamoto, Y., Kawano, K., Kunieda, M., Mizobuchi, T. 2014. Development of coupling beam elements utilizing UHP-SHCC for high-rise R/C building. In Schlangen, E., Sierra Betran, M.G., Lukovik, M., Ye, G. (Eds) Proceedings of the 3rd RILEM Conference on Strain-Hardening Cementitious Composites; pp. 409-416.

[3] Kunieda, M., Rokugo, K. 2006. Recent progress on HPFRCC in Japan. Journal of Advanced Concrete Technology 4 (1) 1933.

[4] Li, V.C., Lepech, M. 2004. Crack resistant concrete material for transportation construction. In Transportation research board $83^{\text {rd }}$ annual meeting, Washington, D.C., compendium of papers. Paper 044680.

[5] Lepech, M.D., Li, V.C. 2009. Application of ECC for bridge deck link slabs. Materials and Structures 42: 1185-1195.

[6] Mechtcherine, V. 2013. Novel cementbased composites for the strengthening and repair of concrete structures. Construction and Building Materials 41: 365-373.

[7] Lukovik, M., Savija, B., Schlangen, E., Ye, G. 2014. Damage induced by continued corrosion in concrete repair systems. In Schlangen, E., Sierra Betran, M.G., Lukovik, M., Ye, G. (Eds) Proceedings of the 3rd RILEM Conference on Strain-Hardening Cementitious Composites; pp. 269-278.

[8] Lukovik, M., Dong, H., Savija, B., Schlangen, E., Ye, G., Van Breugel, K. 2014. Tailoring strain-hardening cementitious composite repair systems through numerical experimentation. Cement and Concrete Composites 53: 200-213.
[9] Kamal, A., Kunieda, M., Ueda, N., Nakamura, N. 2008. Evaluation of crack opening performance of repair material with strain hardening behavior. Cement and Concrete Composites 30: 863-871.

[10] Ohtsu, M. 1996. The history and development of acoustic emission in concrete engineering. Magazine of Concrete Research 48: 321-330.

[11] Shiotani, T., Aggelis, D.G., Makishima, O. 2007. Global monitoring of concrete bridge using acoustic emission. Journal of Acoustic Emission 25: 308-315.

[12]Ohno, K., Ohtsu, M. 2010. Crack classification in concrete based on acoustic emission. Construction and Building Materials 24: 2339-2346.

[13] Grosse, C., Reinhardt, H., Dahm, T. 1997. Localization and classification of fracture types in concrete with quantitative acoustic emission measurement techniques. NDT\&E International 30 (4): 223-230.

[14] Aggelis, D.G., Soulioti, D.V., Sapouridis, N., Barkoula, N.M., Paipetis, A.S., Matikas, T.E. 2011. Acoustic emission characterization of the fracture process in fibre reinforced concrete. Construction and Building Materials 25: 4126-4131.

[15] Soulioti, D., Barkoula, N.M., Paipetis, A., Matikas, T.E., Shiotani, T., Aggelis, D.G. 2009. Acoustic emission behavior of steel fibre reinforced concrete under bending. Construction and Building Materials 23: 3532-3536.

[16]Aggelis, D.G., Soulioti, D.V., Barkoula, N.M., Paipetis, A.S., Matikas, T.E. 2012. Influence of the fiber chemical coating on the acoustic emission behavior of steel fiber reinforced concrete. Cement and Concrete Composites 34: 62-67.

[17] Carpinteri, A., Lacidogna, G., Manuello, A. 2007. An experimental study on retrofitted fiber-reinforced concrete beams using acoustic emission. In: Carpinteri, A., Gambarova, P.G., Plizzari, G.A. (Eds) Proceedings of the $6^{\text {th }}$ International FraMCoS-6 Conference; pp. 1061-1068.

[18]Paul, S.C., Pirskawetz, S., Van Zijl, G.P.A.G, Schmidt, W. 2015. Acoustic 
emission for characterizing the crack propagation in strain-hardening cementbased composites (SHCC). Cement and Concrete Research 69: 19-24.

[19] Mechtcherine, V., Millon, O., Butler, M., Thoma, K. 2011. Mechanical behavior of strain-hardening cement-based composites under impact loading. Cement and Concrete Composites 33:1-11.

[20]Curosu, I., Mechtcherine, V., Millon, O. 2016. Effect of fiber properties and matrix composition on the tensile behavior of strain-hardening cement-based composites (SHCCs) subjected to impact loading. Cement and Concrete Research 82:23-35. 